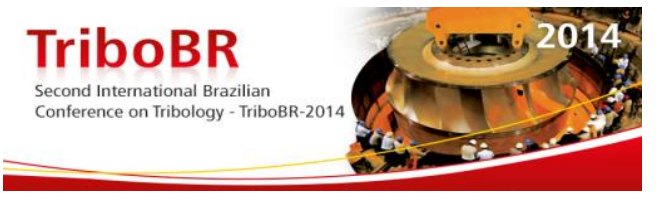

\title{
MASTER PLAN OF LUBRIFICATION: HOW TO IMPLEMENT AN EFFICIENT LUBRICATION PLAN IN THE MINING SECTOR*
}

\author{
Angelo dos Reis Magalhães ${ }^{1}$ \\ Adilson Leite Araujo 2 \\ Baltazar Agenor Bailona ${ }^{3}$ \\ Pedro Henrique Cardoso Furtado 4 \\ Hugo Leonardo Freitas 5 \\ Marcos Alexsandro Reis ${ }^{6}$
}

\begin{abstract}
Brazilian companies have adopted in recent years new management practices to remain competitive. Specialized consulting in asset management progressively creates or adapts new techniques in order to increase availability and reduce manufacturing costs, maximizing profits. New engineering concepts were acquired and implemented by executives in all business segments. Techniques, such as FMEA, RCM, LCC, Pas 55, Reliability studies by Monte Carlo simulations, among others, have become increasingly recognized as important tools to enhance managerial performance. Besides these techniques, this study suggests the importance of adequate structuring of a lubrication program, as a critical success factor for the reliability of any asset. Through a case study developed with a company in the mining sector, this work proposes the development of a master plan for lubrication based on three pillars: People, Equipment and Management system. Practices and care with lubricants, hydraulic fluids and coolant, until its point of application, shall be evaluated to ensure a correct contamination control and a high level of assets availability. This discussion sheds light onto other benefits of this process, including occupational health and safety; ergonomics; environment and sustainability.
\end{abstract}

Keywords: Master plan of lubrication; Asset management; Reliability and availability; Contamination control.

1 Master degree mechanical engineer M.Sc., Engineer, reliability engineering, Anglo American, Conceição do Mato Dentro, Minas Gerais, Brasil.

2 Electrical engineer, Engineering coordinator, reliability engineering, Anglo American, São João da Barra, Rio de Janeiro, Brasil.

3 Ph.D. mechanical engineer, Specialist engineer, reliability engineering, Anglo American, Conceição do Mato Dentro, Minas Gerais, Brasil.

4 Mechanical engineer, Engineer, reliability engineering, Anglo American, Conceição do Mato Dentro, Minas Gerais, Brasil.

5 Mechanical engineer, Specialist engineer, maintenance plant, Conceição does Mato Dentro, Minas Gerais, Brasil.

6 Mechanical engineer, Engineer, reliability engineering, Conceição do Mato Dentro, Minas Gerais, Brasil.

\footnotetext{
* Technical contribution to the $2^{\text {nd }}$ International Brazilian Conference on Tribology - TriboBR 2014, November $3^{\text {rd }}$ to $5^{\text {th }}, 2014$, Foz do Iguaçu, PR, Brazil.
} 


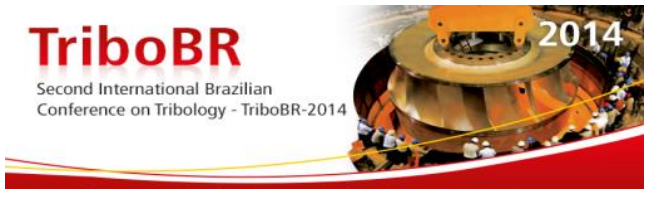

\section{INTRODUCTION}

Maintenance costs in mining companies comprise a considerable portion of the total cost of operation (4.4\% of the gross revenues). [1]

Therefore, it is a target for projects aiming at reducing costs. [2]

The challenge of the maintenance department is exercising its key functions with minimal impact on production and ensuring availability of equipment with appropriate costs.

The Minas Rio Project was acquired by Anglo American in 2008. Among all projects carried by this company around the world, Minas Rio corresponds to the main highest investment, and consists of four areas: mine, beneficiation plant, pipeline and filtering. This project links, linking the towns of Conceição do Mato Dentro to São João da Barra through a pipeline that has an extension of $525 \mathrm{~km}$. The investment is estimated in 8.8 billion dollars. [3]

In order to maximize both objectives of availability and use of the Minas Rio project assets, the maintenance engineering team is in charge of developing asset management practices, based on tools like Reliability Centered Maintenance (RCM), Failure Mode and Effects Analysis (FMEA), Life Cycle Costs (LCC), Lost Profile, Predictive techniques, ISO 55000, on-line monitoring, telemetry and others systems, directing all efforts to build a robust and reliable system.

The reliability management system stresses the importance of the Master Plan of Lubrication - MPL, as proactive maintenance practice on all sites of the project, from the mine to the filtering site, with the objective of achieving excellence in the activities of lubrication - comprising both engineering, planning or execution activities. That delivers value and sustains the firm's commitment to physical availability with low costs.

\subsection{Objectives}

To demonstrate the strategy of the master lubrication plan aimed at reliability, showing the actually status.

\subsection{Bibliographic Review}

Large companies have identified the importance of a good lubrication plan to reduce surface degradation caused by mechanical wear.

Rabinowicz emphasizes the stratification of equipment's' utility loss, according to the following (figure 1). [4]

Where:

$\rightarrow 70 \%$ of the components failures are related to surface degradation;

$\rightarrow$ With $50 \%$ caused by failures of mechanical wear degradation;

$\rightarrow$ And $20 \%$ caused by corrosion failures.

* Technical contribution to the $2^{\text {nd }}$ International Brazilian Conference on Tribology - TriboBR 2014, November $3^{\text {rd }}$ to $5^{\text {th }}, 2014$, Foz do lguaçu, PR, Brazil. 

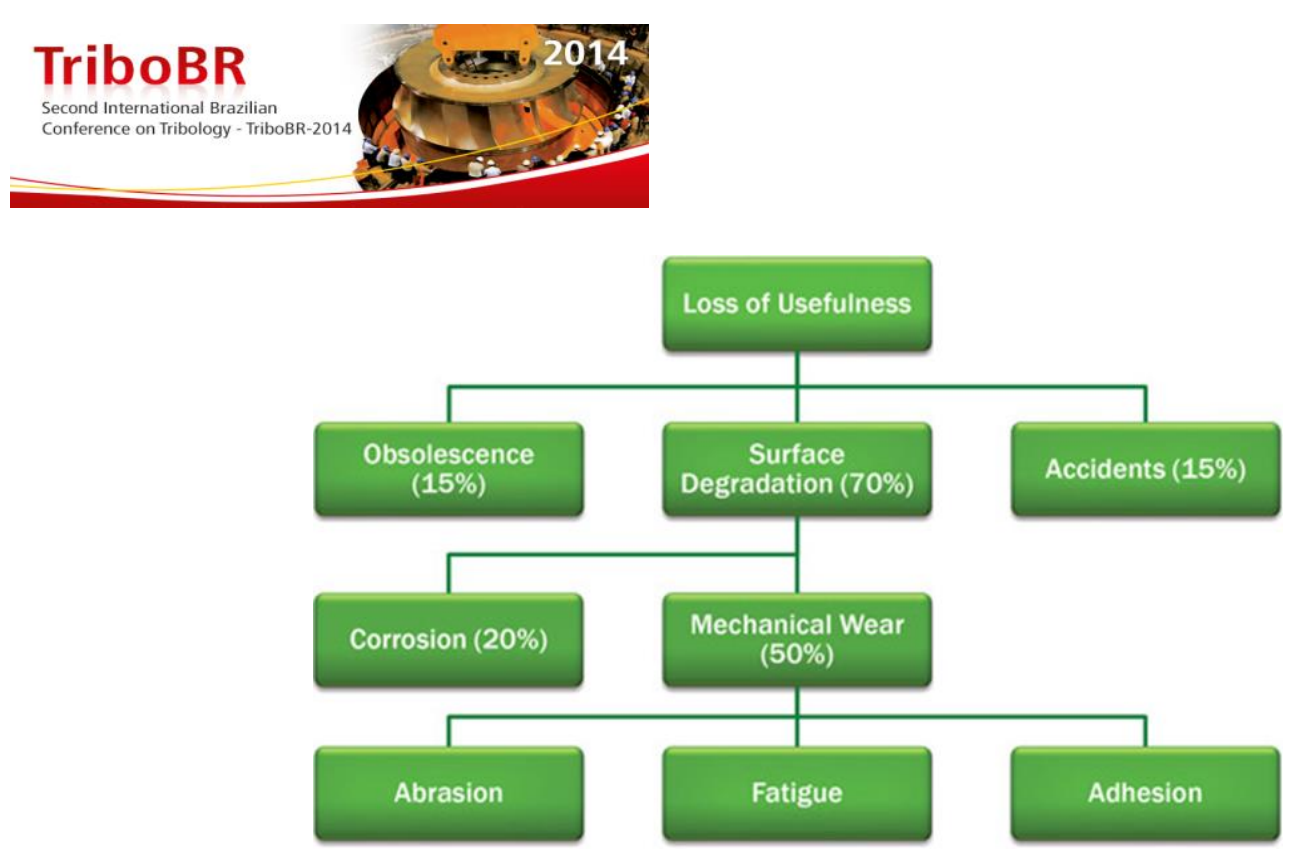

Figure 1: Loss of usefulness [4].

To have a good lubrication practice is necessary to understand: contamination, lubricant contamination control, contaminant types, and standards regarding degrees of cleaning of fluids.

Contamination is a mixture of a contaminant with the lubricant. Contamination may be internal or external.

- Internal contamination - Occurs when there is already wearing of machine elements.

- External contamination - Occurs when introducing any material in the lubricant of the machine.

External contamination can occur when adding oil or when there is a leak in the equipment, because if there is space to leak oil there is concomitantly the possibility of entry of contaminants.

Contaminant is any material that mixes with the lubricant that can cause equipment damage. There are three types of contaminants: Solid, Liquid and Gas.

- Solid Contaminant - are particles of sand, parts of material from machine elements or material from the production process.

- Liquid Contaminant - water, liquid product that is being produced or transported, or other kinds of oils which are not compatible with the lubricant oil equipment

- Gas Contaminant - Atmospheric air with humidity, or a gas that mixes with the lubricating oil.

Contamination control is carried through regular sample collections of lubricants of equipment. While collecting oil sample in a machine, one shall have two objectives in mind:

Examining the condition of the lubricant and identifying the condition of the equipment. A sample consists of a quantity of the lubricant that has the real characteristics and properties of the total. Proper sampling is the starting point for assuring the success of predictive maintenance.

Careful attention to collect the lubricant for analysis is an imperative to an effective result.

The particles which are important for analysis are the ones generated recently. The collection point should be the place with a large amount of new particles in a region of great agitation.

The most relevant tests include: physicochemical analysis, atomic absorption spectrophotometry, particle counting and morphological analysis of contaminants and wear particles.

* Technical contribution to the $2^{\text {nd }}$ International Brazilian Conference on Tribology - TriboBR 2014, November $3^{\text {rd }}$ to $5^{\text {th }}, 2014$, Foz do lguaçu, PR, Brazil. 
For Fitch, analysis of the lubricant in use can detect wear elements during normal operation, external contamination or degradation of the oil used. In other words, all health conditions, contamination and wear. [5]

The classification of the level of cleanliness of lubricating fluids follows the IS0 4406 and NAS 1638 standards. Since 1964, these questions are targets for research and improvements.

The NAS standard is old and has been widely used, but does not have much precision in sizing the filtering process. The ISO standard has a higher accuracy, because it measures solid particles in three basic dimensions: 4, 6 and 14 microns. It had its first official release in 1987 and the latest revision dated 1999, the latter being the most widely used nowadays.

The analysis is done by electronic equipment capable of counting particles or comparison tests using a membrane. The result is interpreted as: the lower number of particles, better cleaned is the fluid.

A new fluid throughout its logistics process - from lubricant stock in the producer until the lubrication point - suffers constant increments of contaminants. Consequently, it is crucial to understand the health of the fluid before any application.

The evolution of the standards of cleanliness levels is given by (Figure 2).

\begin{tabular}{|c|c|c|}
\hline ISO 4406 - 1999 & ISO 4406 - 1999 & NAS 1638 CLASS \\
\hline $13 / 11 / 8$ & $11 / 8$ & 2 \\
\hline $14 / 12 / 9$ & $12 / 9$ & 3 \\
\hline $15 / 13 / 10$ & $13 / 10$ & 4 \\
\hline $16 / 14 / 9$ & $14 / 9$ & - \\
\hline $16 / 14 / 10$ & $14 / 10$ & 5 \\
\hline $17 / 15 / 9$ & $15 / 9$ & - \\
\hline $17 / 15 / 10$ & $15 / 10$ & - \\
\hline $17 / 15 / 12$ & $15 / 12$ & 6 \\
\hline $18 / 16 / 10$ & $16 / 10$ & - \\
\hline $18 / 16 / 11$ & $16 / 11$ & - \\
\hline $18 / 16 / 13$ & $16 / 13$ & 7 \\
\hline 19/17/12 & $17 / 12$ & $=$ \\
\hline $19 / 17 / 14$ & $17 / 14$ & 8 \\
\hline 20/18/12 & $18 / 12$ & - \\
\hline $20 / 18 / 13$ & $18 / 13$ & - \\
\hline $20 / 18 / 15$ & $18 / 15$ & 9 \\
\hline 21/19/13 & $19 / 13$ & - \\
\hline $21 / 19 / 16$ & $19 / 16$ & 10 \\
\hline $22 / 20 / 13$ & $20 / 13$ & - \\
\hline $22 / 20 / 17$ & 20/17 & 11 \\
\hline
\end{tabular}

Figure 2: Comparative of standards of fluid cleanliness degree (source: PDL Anglo American).

According to Scott, there are significant gains in reliability by focusing in the improvement of the cleanliness level of any compartment lubricant or hydraulic fluid. Case studies demonstrate the extended life of mechanical components such as hydraulic systems, diesel engines, bearings, sleeve bearings, turbo machinery and gearboxes due the improvement of the cleanliness level according to ISO standard.

\section{[6]}

Gains in life extension given by solid decontamination are presented in (Table 1). In this case, improving the cleanliness of */24/21 to * / 14/11 we have the following results:

Hydraulic: Extension service life $>10$ times

Bearings: Extension service life of 7 times

Sleeve bearings and turbines: Extension service life of 8.5 times

Gearboxes: Extension of shelf life of 6 times

* Technical contribution to the $2^{\text {nd }}$ International Brazilian Conference on Tribology - TriboBR 2014, November $3^{\text {rd }}$ to $5^{\text {th }}, 2014$, Foz do Iguaçu, PR, Brazil. 

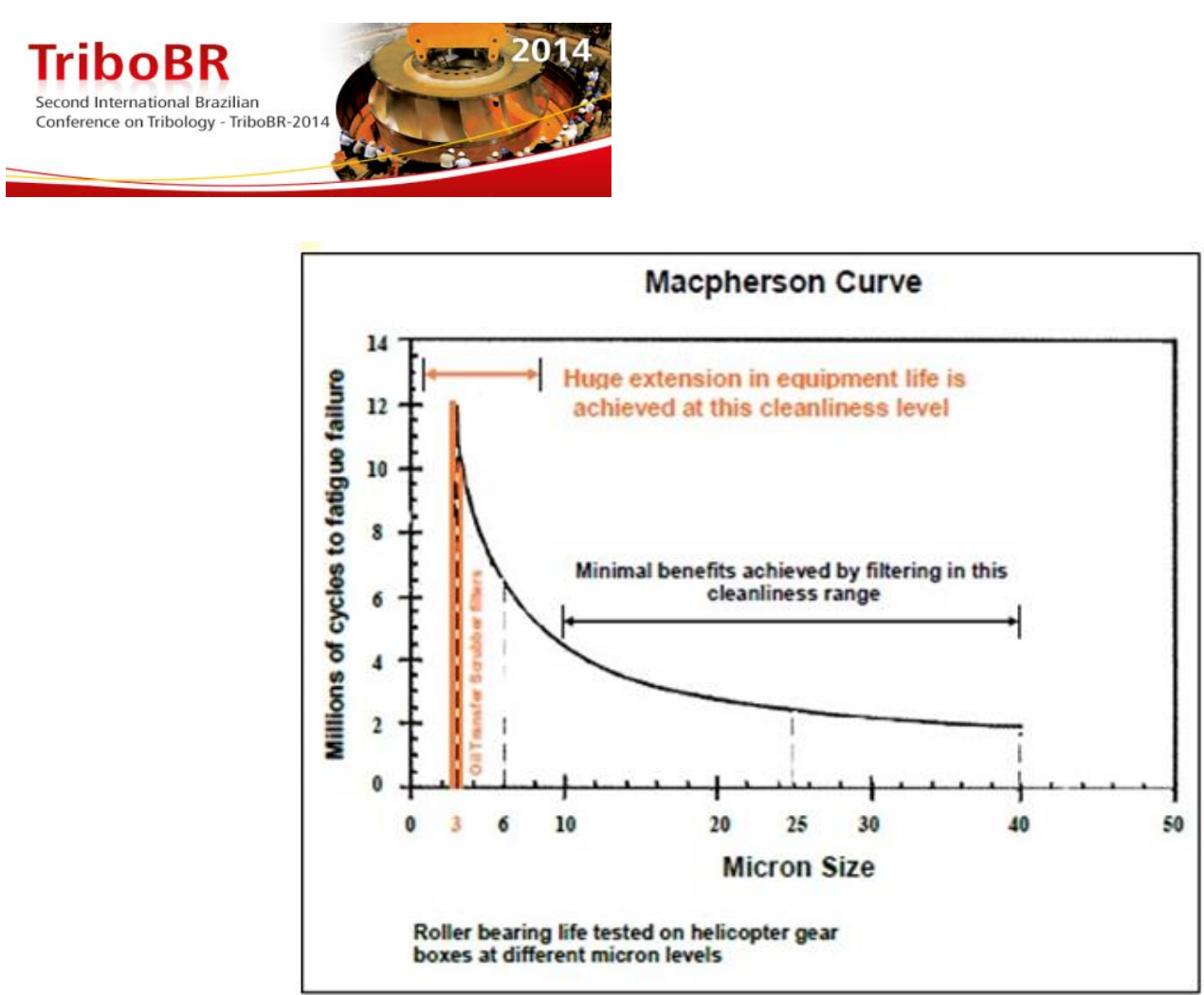

Figure 3: Extension of life $x$ size of particle in micron [7].

\section{MATERIAL AND METHODS}

The Master Plan for Lubrication - designed to meet the reliability requirements of physical assets in the Minas Rio project from Anglo American - was developed through Ishikawa, by using 3M diagram (labor, machine and method) to define the pillars of the plan: people, equipment and method.

People: this pillar covers all concerns with qualification of technical professionals responsible for lubrication, supervisors, coordinators and engineers involved. They are important to define strategies of competences and recycling of knowledge, in order to take highly qualified professionals at all levels, ensuring knowledge, skills and attitudes appropriate to the achievement of goals, as established by the ISO 9001:2008 standard.

It was considered for human resources qualification planning: training requirements and body of knowledge proposed by ICML "International Council for Machinery Lubrication" and its international certifications and MLTI MLTII "machinery lubrication technician", as well as international certifications MLAI, MLAll and MLAIII, "machine lubricant analyst" in accordance with standard ISO 184364. [8]

The MLA certification was directed to the staff of predictive maintenance, and the MLT to all engineers, managers and oilers. As the objective is to provide the highest level of certification in each field, a schedule of training needs had been properly planned for the triennium 2015/2017.

Equipment: This pillar deals with the entire infrastructure necessary for good practice to control the contamination of lubrication. It sets minimum structures for lubrication room, specification of equipment for storage, handling and application of lubricants, specification of offline filtration systems, laboratory equipment and devices to shield equipment in the field, such as vents, valves collections, couplers, drains, feeders, besides the minimum infrastructure required for managing waste from this field, such as contaminated oils, contaminated filters and rags.

Due to the environment in which our mine, plant, pipeline and filtering equipment operate - with high load of contaminants inherent in our own process -, specifying is fundamental to obtain absolute control of contamination in the equipment.

* Technical contribution to the $2^{\text {nd }}$ International Brazilian Conference on Tribology - TriboBR 2014, November $3^{\text {rd }}$ to $5^{\text {th }}, 2014$, Foz do lguaçu, PR, Brazil. 


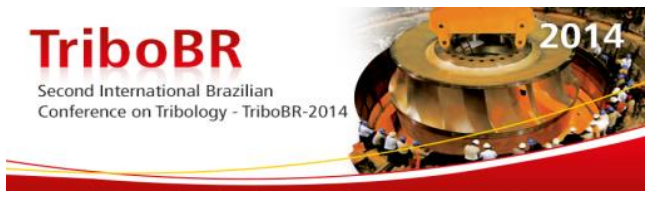

Strategically within this pillar was set that all oils must be filtered before use, at Lube Room of lubrication, seeking a cleanliness level of 15/13/10.

All the Lube Room infrastructure was designed in order to have the ability to filter oils while receiving them, during the storage period (recirculation), and if necessary at the time of application or with the equipment in use, besides off-line filtration equipment and dehydrators, together with equipment for primary analysis, which must be enough for particle counting according to NAS and ISO standards and water percentage.

The mining equipment is also susceptible to external contamination, mainly by vents, levels, power plugs and drain. Because of the cost it is recommended to clean the compartments exposed to contamination. Subsequently, it is necessary to elaborate a detailed study on these components, evaluating the gaps and providing the necessary corrections, making them shielded against external contamination oils.

As a best practice of lube room, the layout of the plant infrastructure is presented, with its storage and filtering containers, "oil safe" containers for small volumes, "offline" systems of filtration, dehydrator, area for waste treatment, area of grease lubrication and field laboratory. (Figure 4)

The infrastructure of the mine is equipped with tank farm to receive the bulk oil, filtration system to receive the lubricant, recovery area for filtering and specific dehydration and dedicated to the mobile equipment, central of waste, box of lubrication and vehicles for lubricants and diesel supply field. (Figure 5)

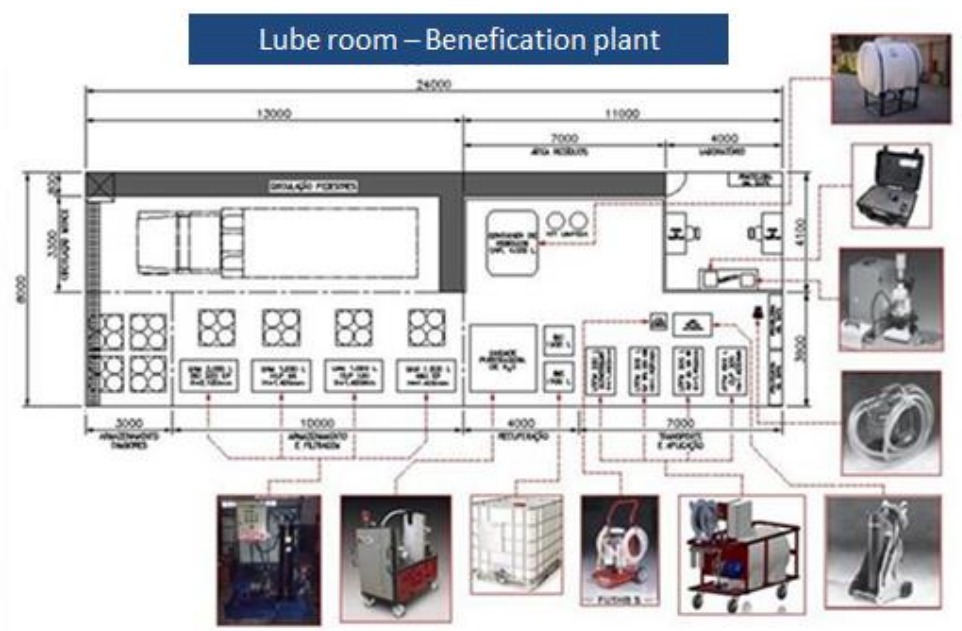

Figure 4: Layout of the lube room in the beneficiation plant (source: PDL Anglo American).

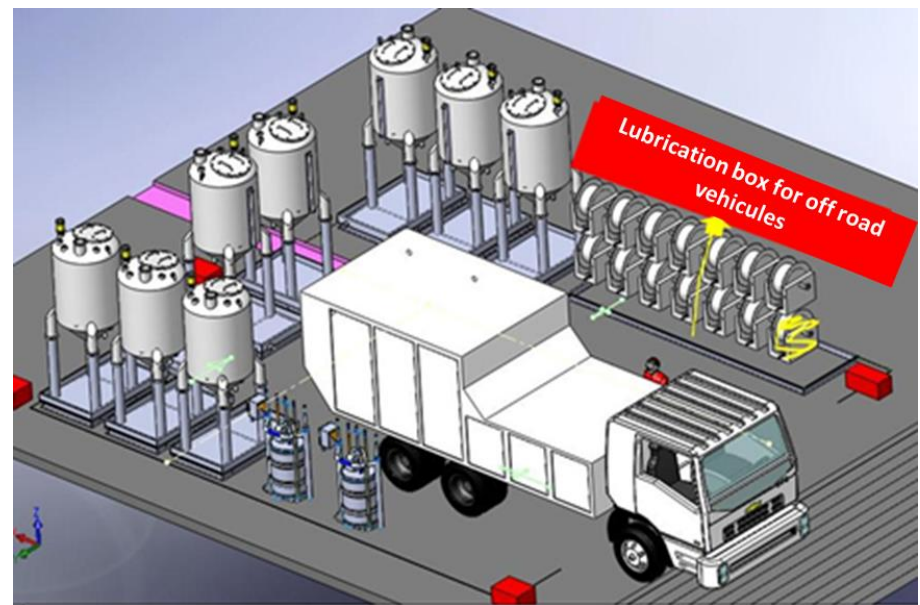

Figure 5: Mining Infrastructure - Box of lubrication (source: PDL Anglo American)

* Technical contribution to the $2^{\text {nd }}$ International Brazilian Conference on Tribology - TriboBR 2014, November $3^{\text {rd }}$ to $5^{\text {th }}, 2014$, Foz do Iguaçu, PR, Brazil. 
To promote a process of continuous improvement, audits of maturity are going to planned to be conducted and held annually by an independent company.

It was defined the main indicators as: Compliance with lubrication plan, compliance with collection plan, compliance with the inspection plan, lubricant consumption, "down-time" for lubrication, alarm index of the oil program analysis, number of recommendations alerted $x$ corrections carried out, costs of lubrication and waste generated $x$ treaties.

\section{RESULTS}

\subsection{People Pillar}

3.1.1 Performed MLTI training, certifying fourteen professionals with ICML.

3.1.2 Participation of one hundred employees in two workshops led by experts in filtering, in order to level the knowledge on the subject, with the effective participation of the team of mechanics and lubrication.

3.1.3 Prepared and guided the process of awareness about the importance of basic lubrication and reliability, using the methodology of communication booklets, with a simple, clear and easy language for employees.

\subsection{Equipment Pillar}

3.2.1 All planned infrastructure was acquired, with an investment of US $\$ 3.500 .000$

3.2.2 Performed 64 projects to shield equipment, with an approximate investment of US\$ 438.000

\subsection{Method Pillar}

3.3.1 Prepared plans of lubrication and collecting for all the sites of the Minas-Rio Project

3.3.2 Plans were uploaded into the SAP platform;

3.3.3 Defined key indicators of management.

\subsection{Other results}

The acquired infrastructure reduces handling drums and plastic drums at all sites, significantly contributing to improving safety and ergonomic aspects of lubrication activities, as well as minimizing the chances of spillage and environmental accidents, deriving from excessive handling of lubricant.

\section{CONCLUSIONS}

This work clearly and objectively presented all the strategies developed in a master plan aimed at lubrication reliability, highlighting the benefits of good management of this field, and their results.

Evolution stages of the master plan are already adequately planned and new articles will be created in future.

* Technical contribution to the $2^{\text {nd }}$ International Brazilian Conference on Tribology - TriboBR 2014, November $3^{\text {rd }}$ to $5^{\text {th }}, 2014$, Foz do lguaçu, PR, Brazil. 


\section{DISCUSSIONS}

Because it is a broad subject, it is not intended to exhaust the subject with a single article, but rather to contribute positively to the academic and business setting by exposing a management practice and careful lubrication which is nowadays a reality within our company, hopefully motivating further research and studies within the mining sector. The expectation of becoming a benchmarking project in Brazil is expressive and perfectly possible.

\section{Acknowledgments}

Thanks to the management team of Anglo American especially to Marcelo Barcelos Gomes and Leonardo David de Souza, whose believe in the potential of the MPL, providing resources for achievement, and encouraging all staff for excellence level.

\section{REFERENCES}

1 Kardec, Alan. Nascif, Júlio. (2010). Manutenção Função Estratégica, Qualitymark Editora Ltda. - Rio de Janeiro, p 64; 107.

2 Knights, Peter F., "Analyzing Breakdowns", Mining Magazine, Vol. 181 No.3, pp.165-71, September, 1999.

3 Projeto Minas Rio, [internet]. Belo Horizonte, [cited 2014 June 20]. Available from: http://minasrio.angloamerican.com.br/o-projeto/anglo-american-no-brasil/

4 Rabinowicz, Ernest. (1995). Friction and Wear of Materials Second Edition, Wiley- interscience publication, pp 59; 62 - New York.

5 J. Fitch. Reliable Plant magazine. July 2012

6 Scott, Robert. Fitch, Jim et Lounger, Lloyd. (2012). the Practical Handbook of Machinery Lubrication - 4th Edition, Tulsa - USA.

7 Machinery lubrication magazine Macpherson curve,[internet].Tulsa USA, [cited 2014 June 06]. Available at:http://www.machinerylubrication.com/Read/1291/lubricant-cleanliness

8 ICML International council for machinery lubrication, [internet]. USA, [cited 2014 June 10]. Available from: http://lubecouncil.org/exams/Default.aspx

9 Ludema, K. (1996) Friction, Wear, Lubrication: A Textbook in Tribology, CRC Press, Boca Raton, FL USA

10 Denis, J., J Briant and J. Hipeaux (1997) Lubricant Properties Analysis \& Testing. Editions TECHNIP, Paris, France

11 International Organization for Standardization, ISO 4406:1999(E), "Hydraulic fluid power - Fluids - Method for coding the cleanness level.

* Technical contribution to the $2^{\text {nd }}$ International Brazilian Conference on Tribology - TriboBR 2014, November $3^{\text {rd }}$ to $5^{\text {th }}, 2014$, Foz do Iguaçu, PR, Brazil. 